Compar $i$ son of wool en eco- $f$ ri endl y ant $i$ - $f$ el ting treat ment with $\mathrm{cl}$ assi $\mathrm{c}$ ant $\mathrm{i}-\mathrm{felting}$ procedures

\begin{tabular}{|c|c|}
\hline 著者 & Mbr i M, Nat sudai r a M t suo \\
\hline $\begin{array}{l}\text { j our nal or } \\
\text { publ i cat } i \text { on title }\end{array}$ & Texti le Research Journal \\
\hline vol une & 83 \\
\hline nunber & 2 \\
\hline page $r$ ange & $208-215$ \\
\hline year & 2013 01- 01 \\
\hline URL & ht t p: //hdl . handl e. net /2297/33447 \\
\hline
\end{tabular}




\title{
Comparison of Woolen Eco-friendly Anti-felting Treatment with Classical Anti-felting Procedures
}

\begin{abstract}
The development of an eco-friendly anti-felting treatment based on calcium hypochlorite and hydrogen peroxide $\left(\mathrm{Ca}(\mathrm{ClO})_{2}+\mathrm{H}_{2} \mathrm{O}_{2}\right)$ system, so-called MEFT (Mori Eco-friendly Treatment) process is reported in this paper. By applying this process, excellent properties in anti-felting and fabric handle were imparted to wool fabrics without perceptible change in the breaking strength, whiteness and dyeability. The other properties such as hydrophilicity, descaliness and softness were comparable with the other processes such as Chlorination, NARS and Caroat. In the process of NARS, whiteness and dyeability were found to be excellent. The lowest breaking strength and elasticity property of shearing may be due to the presence of sodium hydroxide in the treating solution at relatively higher $\mathrm{pH}$. Anti-felting property based on various other oxidative and non-oxidative treatments was compared and the rank was obtained approximately in the order; Chlorination $>$ NARS $=$ MEFT $>$ Plasma $>$ Caroat.
\end{abstract}

Key words: Anti-felting, Wool, Eco-friendly, Fabric handle, Color intensity, Scale appearance

\section{Introduction}

Wool is high quality fiber materials with characteristic properties excellent in many respects as compared to synthetic fibers[1]. Especially, the surface property is a potentially important factor which determines the superiority. However, undesirable felt-shrinkage generating by home washing is mainly associated with the surface properties of wool. There have been many shrink-proofing methods developed by applying a variety of surface modification techniques, and shrink-resistant wool materials have also been produced and 
commercialized widely. However, the production has encountered not only environmental problem, but also deterioration of mechanical and surface properties of wool fibers, such as fabric handle, dyeability and so on.

There are many processes available for imparting shrink resistance to wool, and the procedures could be mainly divided into three categories: (i) Resin processes, (ii) Kroy-Hercosett processes [2] of polymer application after chlorination treatments, and (iii) Oxidation processes. At present, majority of world production of machine washable wool is wool with resin treated process by applying polyurethane to garments. Although the effectiveness of resin treatments are approved, extensional elasticity, softness, fabric handle and other properties characteristic of wool are severely lost. In Kroy-Hercosett continuous processes for tops, wool is more or less damaged by a lot of chlorine. Strong acid is used in this process and required a neutralization/anti-chlorination procedure to remove residual chlorine, which causes AOX (Absorbable Organic Halogens) and pollution of wastewater problems.

Thirdly, the oxidative treatment system is a chlorine exhaustion method developed by Bereck and Reincke[3]. This is two step process comprising of Basolan DC, which is a commercial DCCA method in BASF Co. in Germany, and subsequent hydrogen peroxide treatments. This is interesting process performing a full exhaustion of chlorine within the texture of wool fabrics and results in no or little harmful active chlorine in waste water, since peroxide as the antichlor agent acts with chlorine and thus the chlorine used can be significantly reduced and wool damage can also be reduced to give a softer handle by removing scales on fiber surface. This process can be carried out easily by using a conventional batch type small-scale chlorination vessel at a lower temperature for long time, and thus temperature control is sometimes difficult due to change in climate and goes to unevenness in processing. 
Recently, Cardamone and Yao[4] reported a novel process, the so-called ARS (Agricultural Research Service, USA) method for wool bleaching and shrink-proofing treatment using alkaline $\mathrm{H}_{2} \mathrm{O}_{2}$ systems and followed by enzyme treatment at near-room temperature conditions. Since this method was dangerous to fabric handle because of using strong alkali, NARS (improved new method of ARS by Mori)[5] method was adopted as a modified method. The effectiveness of this treatment will be described in the latter section of this paper

In the present research for MEFT (Mori Eco-friendly Treatment) process, which involves the reactions of $\mathrm{Ca}(\mathrm{ClO})_{2}$ with $\mathrm{H}_{2} \mathrm{O}_{2}$, the most adequate treatment conditions of time, temperature, and $\mathrm{pH}$ were selected and anti-felting performance, fabric handle and color intensity were investigated. These properties imparted to the treated fibers and fabrics were compared with the results obtained from various other oxidative and non-oxidative treatment systems. MEFT is a modified method of ARS method and developed by the hint of Bereck and Reincke[3]. Improvement of both points such as environmental pollution and AOX control was aimed in this method. By using calcium hypochlorite, which is easy to decompose compared to DCCA, the aim is achieved and yellowing problem brought about by chlorination is also solved. If we compare the amount of chlorine used in MEFT process with DCCA, it decreases from $3.0 \%$ to $2.4 \%$, means the reduction of $20 \%$ of effective chlorine. This value contributes a lot to eco-friendly treatment of wool fabrics.

\section{Experimental}

\subsection{Materials}

Two kinds of fabric samples M and C were prepared. Sample M was 2/2-twill fabric made of 1/40 (250 dtex) Merino wool (100\%) yarn in warp and weft and weighed $94 \mathrm{~g} / \mathrm{m}^{2}$, and sample C was plain weave made of 1/30 (333 dtex) New Zealand Corriedale wool (100\%) yarn in warp and weft and $134 \mathrm{~g} / \mathrm{m}^{2}$, respectively. A standard clear finishing was done without 
milling and raising. For the measurement of breaking strength of yarns, yarns were treated in the yarn state by the same method as fabrics and used for experiment.

\subsection{Preparation of Various Kinds of Shrink-Resistance Treatment Samples}

\subsubsection{Chlorination Treatment}

Fabric samples were dipped in water at 20 to $25{ }^{\circ} \mathrm{C}$ with liquor ratio $1: 20$, and the amount corresponding to $0.05 \%$ non-ionic surfactant was added as a penetrating agent, and then the bath was rotated until the samples get perfectly soaked wet. Then, $3.0 \%$ (on the weight of fabric $=$ o.w.f. as active chlorine) of DCCA (dichloroisocyanuric acid) and 5 \% (o.w.f.) of sodium pyrophosphate $\left(\mathrm{Na}_{4} \mathrm{P}_{2} \mathrm{O}_{7} \cdot 10 \mathrm{H}_{2} \mathrm{O}\right)$ were added and followed by adding acetic acid for adjusting $\mathrm{pH}$ within the range of 5.5 - 6.0 and maintained for $50 \mathrm{~min}$ at this temperature. The solution temperature was then raised to $35^{\circ} \mathrm{C}$ in $10 \mathrm{~min}$ and maintained for $20 \mathrm{~min}$, and the amount corresponding to $6 \%$ (o.w.f.) of sodium hydrogen sulfite $\left(\mathrm{NaHSO}_{3}\right)$ was further added and maintained 10 min after the temperature was raised to $60{ }^{\circ} \mathrm{C}$. The treated fabrics were rinsed and air-dried. The chlorination-treatment samples thus obtained were subjected to property measurements.

\subsubsection{Mori Eco-Friendly Treatment (MEFT)}

Fabric samples were well soaked as described above. Then, 4 \% (o.w.f.) Nisso Hyclon (calcium hypochlorite: $\mathrm{Ca}(\mathrm{ClO})_{2} \cdot 3 \mathrm{H}_{2} \mathrm{O}$ ), which contains $70 \%$ as active chlorine was added to the solution and after standing for $5 \mathrm{~min}, 12 \mathrm{~mL} / \mathrm{L}$ of $\mathrm{H}_{2} \mathrm{O}_{2}$ (35 \%) with $2 \mathrm{~g} / \mathrm{L}$ of sodium pyrophosphate as a peroxide stabilizer and $1 \mathrm{~g} / \mathrm{L}$ of ethylenediaminetetraacetic acid (EDTA) as a sequestering agent were further added under a gentle stirring. The mixed solution $(\mathrm{pH}=$ 5.0) thus obtained was maintained at $40{ }^{\circ} \mathrm{C}$ for $20 \mathrm{~min}$ to complete the reaction of hypochlorite ions with peroxide and subsequently, $6 \%$ (o.w.f.) sodium sulfite and $1 \mathrm{~mL} / \mathrm{L}$ of 
formic acid (80 \%) were added to the solution and adjusted to $\mathrm{pH}=3.0$, and the treatment was further continued at $50{ }^{\circ} \mathrm{C}$ for $10 \mathrm{~min}$. The hydrogen peroxide species remaining in solution were completely reduced with sulfite ions in the acidic environment. Finally, after a gradual cooling, the samples picked up from the solution were rinsed in water and air-dried. The treated samples thus obtained by applying the so-called Mori Eco-Friendly Treatment (MEFT) were subjected to property measurement.

\subsubsection{Caroat Treatment}

Fabric samples were thoroughly soaked as described above. Then, the amount corresponding to 6.0 \% (o.w.f.) Caro's acid (potassium salt of peroxysulfuric acid: $\mathrm{KHSO}_{5}$ ) was added, and the solution $\mathrm{pH}$ was adjusted to 3.5 - 4.0 with acetic acid and maintained at 35 ${ }^{\circ} \mathrm{C}$ for $30 \mathrm{~min}$, and then the solution was drained out from the bath. Again, the samples were dipped in water at $20-25{ }^{\circ} \mathrm{C}$ with liquor ratio 1 : 20 and $5 \%$ (o.w.f.) sodium sulfite was further added and $\mathrm{pH}$ was adjusted to 8.0 by using a $2 \%$ solution of sodium carbonate, and the temperature was raised to $60{ }^{\circ} \mathrm{C}$ and maintained for $10 \mathrm{~min}$, and then the solution was drained out from the bath and finally the treated samples were rinsed in water and then air-dried. The $\mathrm{KHSO}_{5}$-treated samples thus obtained were subjected to property measurements. This process is called Caroat method.

\subsubsection{NARS Treatment}

The treatment was carried out according to NARS (improved new method of ARS)[5] standard process. Compared to ARS [4] method, strength of wool fibers and anti-felting effect of wool fabrics are improved by this method.

\subsubsection{Method of Dyeing}


Treated and untreated wool fabric samples were dyed by using a dyeing machine, Colorpet 12LMP-E (Nissen Co.). The samples were immersed for $10 \mathrm{~min}$ in $0.1 \%$ surfactant solution as a penetrating agent with liquor ratio $1: 20$. Dye was added into the surfactant solution at the temperature of $50{ }^{\circ} \mathrm{C}$ and then the temperature was raised to $100{ }^{\circ} \mathrm{C}$ by $1.5^{\circ} \mathrm{C} / \mathrm{min}$ and maintained for 20 min under a gentle stirring, and the dyeing was further continued for 40 min at $100{ }^{\circ} \mathrm{C}$ in the presence of $2.0 \%$ (o.w.f.) acetic acid (99 \%) for adjusting to $\mathrm{pH} 4.0-4.5$, and thoroughly washed and dried. Dye stuffs used were 1.0 \% (o.w.f.) Irgalan grey BL (C.I. Acid black 58) and 4.0 \% (o.w.f.) C.I. Acid blue 185.

\subsubsection{Plasma Treatment}

Plasma reactor used was a type DSSO-422 (Daia Sinku Co., Ltd.). The discharge frequency was fixed at $13.56 \mathrm{MHz}$. Plasma treatment was carried out by the following procedure. The fiber sample was placed in the reactor, and evacuated at 0.001 Torr $(0.13 \mathrm{~Pa})$, and then argon (Ar) gas was fed into it at a flow rate of $10 \mathrm{~mL} / \mathrm{min}$. The electric power for plasma discharge is fixed at $100 \mathrm{~W}$. The internal pressure of the reactor was maintained at 0.1 Torr (13.3 Pa) during plasma-treatment time $300 \mathrm{~s}$. The treatment samples were finally rinsed in water and air- dried, and the plasma-treated samples were subjected to property measurements.

\subsection{Property Measurements}

\subsubsection{Evaluation of Felt Shrinkage of Wool Fibers}

Aachen felt-ball method, IWTO-20-69 (E) was employed for evaluating the felt shrinkage of wool fibers. The testing machine equipped with a cylindrical vessel, which contains $1 \mathrm{~g}$ of wool sample and $50 \mathrm{~mL}$ of distilled water was rotated three-dimensionally at a speed of $150 \mathrm{rpm}$. After $60 \mathrm{~min}$ had passed, the sample was taken out from the vessel, dried on the 
filter paper in the ambient air for $48 \mathrm{~h}$, and the diameter of felt ball was measured. The degree of felt shrinkage, S (\%) was defined by

$$
\mathrm{S}(\%)=\frac{\left(d_{r 0}-d\right)}{d_{r 0}} \times 100,
$$

where $d$ is the felt ball diameter for either untreated or treated wool sample and $d_{r 0}$ is the reference value of felt ball diameter obtained by rotating the untreated sample in the vessel for $1 \mathrm{~min}$ at $150 \mathrm{rpm}$. Here, it was assumed that at this condition no felting of wool fibers would be generated. In the present study, the fibers for shrinkage measurements were taken from the warp and weft threads constituting fabric samples.

\subsubsection{Evaluation of Fabric Handle}

In this paper, KES-system was used for quantitative evaluation of fabric handle. Changes of mechanical properties and fabric handle were inspected by objective evaluation method using KES-system for untreated and treated wool fabrics. Tensile, bending, shearing and surface properties were measured for both direction of warp and weft yarns, and compressional property was measured for the fabric together with thickness and weight. Fabric size was exactly $20 \mathrm{~cm}$ x $20 \mathrm{~cm}$ and kept more than 24 hour under the conditions of 20 ${ }^{\circ} \mathrm{C}$ and $65 \%$ RH.

\subsubsection{Observation of Surface Morphology}

SEM (JSM-670F) was used for observation of wool surface at direct magnification ranging from 300 to 3000 at $3 \mathrm{kV}, 20 \mathrm{~A}$ after coating the surface with evaporated Pt for $7 \mathrm{~min}$. The samples were taken out from treated fabrics. Samples treated in the state of yarn were also tested.

\subsubsection{Breaking Strength and Elongation of Single Yarn}


According to the method of JIS-L-1095, breaking strength of single yarn was measured by using a tensile tester Shimazu AG-10HNIS. Sample length between clamps was $200 \mathrm{~mm}$, and extension speed was $100 \mathrm{~mm} / \mathrm{min}$. 50 samples were tested and the average value for breaking load $(\mathrm{N})$ was measured. Here, control sample was prepared by immersing the untreated Merino and Corriedale wool fibers in distilled water at $25^{\circ} \mathrm{C}$ for $30 \mathrm{~min}$, dehydrated and air-dried, and the effect of contraction of yarn in aqueous medium was removed. Samples were treated in the state or yarn in this experiment.

\subsubsection{Color Measurement}

Color of sample was measured by spectro-colorimetry Minolta CM-3600D. Power source was D65, visual angel was 10 degree, and sample size was $5 \mathrm{~cm}$ x $5 \mathrm{~cm}$. Dyeing yield was measured from reflection ratio at the maximum absorption wavelength and K/S was calculated using Kubelka-Munk equation. $\quad \mathrm{L}^{*}, \mathrm{a}^{*}, \mathrm{~b}^{*}$ on CIELAB system were obtained for dyed samples and $\mathrm{L}^{*}$ was used for the reference value of dyeing yield. Reflectance of treated wool was measured and L* was calculated according to Kubelka-Munk equation. The whiteness was obtained from the change to the untreated wool fiber.

\subsubsection{Hydrophilic property}

Hydrophilic property was measured according to Byreck method of JIS-L-1096 Waterabsorbency test. A fabric sample with $10 \mathrm{~mm}$ in width and $200 \mathrm{~mm}$ in length was dipped in $2 \%$ C.I.Acid red 116 solution, and absorbed height of water; h (mm), was measured after 10 $\min$.

Water-absorbency; H(\%), was calculated from following equation (2):

$$
\mathrm{H}(\%)=\frac{h}{h \max } \times 100
$$

where, $\mathrm{h}_{\max }$ is the maximum height $(\mathrm{mm})$ at the equilibrium state; that is, after 1 hour, and $\mathrm{h}$ is 
the absorbed height (mm) of each sample.

\section{Result and Discussion}

\subsection{Anti-felting Effect of Variously Treated Wool Fabrics}

Figure 1 shows the comparison of the degree of shrinkage, S (\%) defined by equation (1), for the untreated Merino and Corriedale wool and variously shrink-resistance treated wool fabrics. It can be known that there are no significant differences between the values for the two kinds of wool, but there are considerable differences among the treated fabrics and the effectiveness of chlorine processes is more prominent than that of the other oxidative and plasma treatments. The shrinkage is under $10 \%$ for both Merino and Corridale wool fabrics in the case of Chlorination, NARS, MEFT and Plasma treatment. The application of the present MEFT process is clearly shown to have a level being acceptable for effectiveness of shrink-proofing. The level is similar to that of chlorination. This suggests that the effect of uniform degradation of wool surface is due to the reactions of hypochlorite ions and peroxide as shown in equation (3) [6]:

$$
\mathrm{OCl}^{-}+\mathrm{H}_{2} \mathrm{O}_{2} \rightarrow \mathrm{Cl}^{-}+\mathrm{H}_{2} \mathrm{O}+\mathrm{O}_{2}
$$

\subsection{Fabric Handle}

Differences of mechanical parameters measured by KES-system between each treatment were quite small except 2HG5; that is shearing hysteresis at shear angle 5 degree. The calculated primary hand values such as KOSHI, NUMERI and FUKURAMI were also similar between each treatment. Therefore, 2HG5 (N/m) was adopted as the representative parameter of fabric handle and the results were shown in Figure 2 and discussed here. Comparing with the value of untreated wool, all the fabrics treated with any different processes became to be less recoverable at large shear deformation, especially, fine Merino 
wool had higher value than that of Corriedale. However, there were considerable differences among the treatments, namely, somewhat higher level in Chlorination, and relatively lower in NARS, MEFT, Plasma and Caroat treatments. The value of 2HG5 is sufficiently small by the treatment of MEFT compared to that of Caroat and NARS and it is concluded that MEFT process is available in the point of fabric handle.

\subsection{Observation of Surface Morphology}

Figure 3 shows the surface appearances of the untreated and treated wool fibers. Well-defined contour lines of scale edge can be seen on the surface of the untreated wool fibers. It is shown that no perceptible change is recognized on the surface of plasma treated fibers. However, descaling and smoothing occurs more or less through oxidative treatments and the surface degradation increases in the order: Chlorination $>$ MEFT $>$ NARS $>$ Caroat $=$ Plasma $=$ Untreated. This order is approximately similar order in the degree of anti-felting, i.e., Chlorination $>$ MEFT $=$ NARS $>$ Plasma $>$ Caroat $>$ Untreated. Except for plasma treatment, these relation well accords with many of the theories of felting-shrinkage explained on the basis of the directional frictional effect being responsible for the unidirectional movement of wool fibers during machine washing[7-10]. Plasma treatment may lead to a non-uniform surface modification within fiber or fiber to fiber, resulting in a difficulty for evaluation of felting-shrinkage.

\subsection{Breaking Strength of Treated Yarn}

The breaking strengths of single wool yarns for untreated control and treated samples were shown in Figure 4. All of the chemical treatments tend to lower the breaking strength of yarn. On the contrary, plasma treatment is almost no change in strength as compared with that of the control, suggesting that oxidation and etching reactions occurring plasma 
irradiation may be limited within or in near-scale layers. However, oxidative treatments have considerable effects on cortex region, which is strength bearing component. Figure 4 shows that the breaking strength is decreased in the order: Untreated control = Plasma > MEFT $>$ Caroat $>$ Chlorination $>$ NARS. The present MEFT process well preserves mechanical properties under the controlled reaction conditions of the calcium hypochlorite ions and $\mathrm{H}_{2} \mathrm{O}_{2}$ followed by complete remove of the peroxide species from the fabrics using the reaction with sulfite ions.

\subsection{Hydrophilic Property}

The result of hydrophilicity is shown in Figure 5. It is noted that there is an approximate parallel relationship between K/S (Figure 7) value and hydrophilicity being particularly evident for Merino wool. An extraordinary high level of the hydrophilicity of chlorination suggests that surface damage is considerable. It is of interest that dyeing depends much more on hydrophilicity rather than yellowing due to chlorination.

\subsection{Color Measurement}

Figure 6 shows the whiteness for untreated and treated fabrics. The value of whiteness is significantly improved in NARS and the same levels in MEFT and Caroat, but greatly reduced in Chlorination. The effect of bleaching by MEFT seems to be due to the controlled reactions of equation (3).

Figure 7 shows the K/S values indexing color intensity of dyed sample for untreated and treated fabrics. It is worthy to note that NARS and MEFT processes make a remarkable improvement of the dyeability of the fabrics, i.e., double or more increase as compared to that of untreated sample. It should be further emphasized that for the present MEFT process tippy dyeing observed in practical fabrics was also significantly reduced. 


\section{Conclusions}

By applying the present MEFT (Mori Eco-Friendly Treatment) process, excellent properties in anti-felting and fabric handle were imparted to wool fabrics without perceptible change in the breaking strength, whiteness and dyeability. The other properties such as hydrophilicity, descaliness and softness are comparable with the other processes such as Chlorination, NARS and Caroat. In the process of NARS, whiteness and dyeability were found to be excellent. The lowest breaking strength and elasticity property of shearing may be due to the presence of sodium hydroxide in the treating solution at relatively higher $\mathrm{pH}$.

\section{Acknowledgement}

Authors thank to Dr. Kozo Arai, Director of Keratin Research Association Wool Research Laboratory, Kiryu City, Gunma Prefecture 376, Japan, for his kind discussion and critical reading of the manuscript.

\section{References}

1. John D. Leeder, "Wool - Nature's Wonder Fibre", Australian Textile Publisher, p.1 (1984).

2. D. Feldman, J. R. Mcphee and W. V. Morgen, Textile Manufacturing, 93, 122 (1967).

3. A. Bereck and K. M. Reincke, Melliand Textilberichte,70, 452 (1989).

4. M. Cardamone and J. Yao, Textile Res. J., 74, 555, 565 (2004).

5. M. Mori, applying Japanese Patent, (2011).

6. D.M Lewis, "Ancillary Processes in Wool Dyeing in "Wool Dyeing”", D. M. Lewis, Ed., Society of Dyers and Colourists, p.122 (1992).

7. J. B. Speakman, E. Scott and H. Chang, J. Text. Inst., 24, T273 (1933).

8. E.H. Mercer and R.K. Makinson, J. Text. Inst., 38, T227 (1947). 
9. L. Bohm, J. Soc. Dyers Colour., 61, 278 (1945).

10. A. Hepworth, J. Sikorsky, D. J. Tucker and C.S. Whewell, J. Text. Inst., 60, T513 (1969).

A part of this paper was presented at the 40th Textile Research Symposium in Kyoto, 2011. 


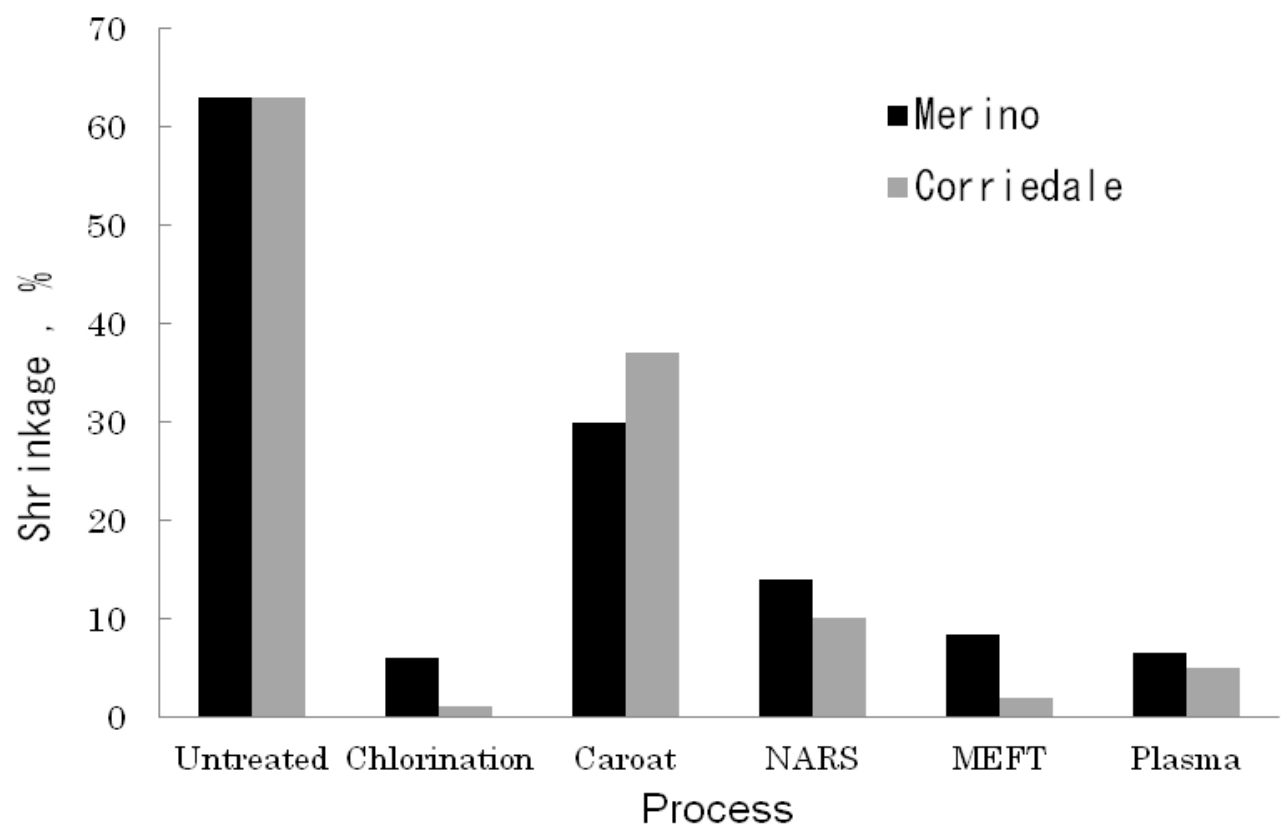

Fig.1 Degree of felting shrinkage, S(\%) for various shrink-resistance treatment of wool fabrics.

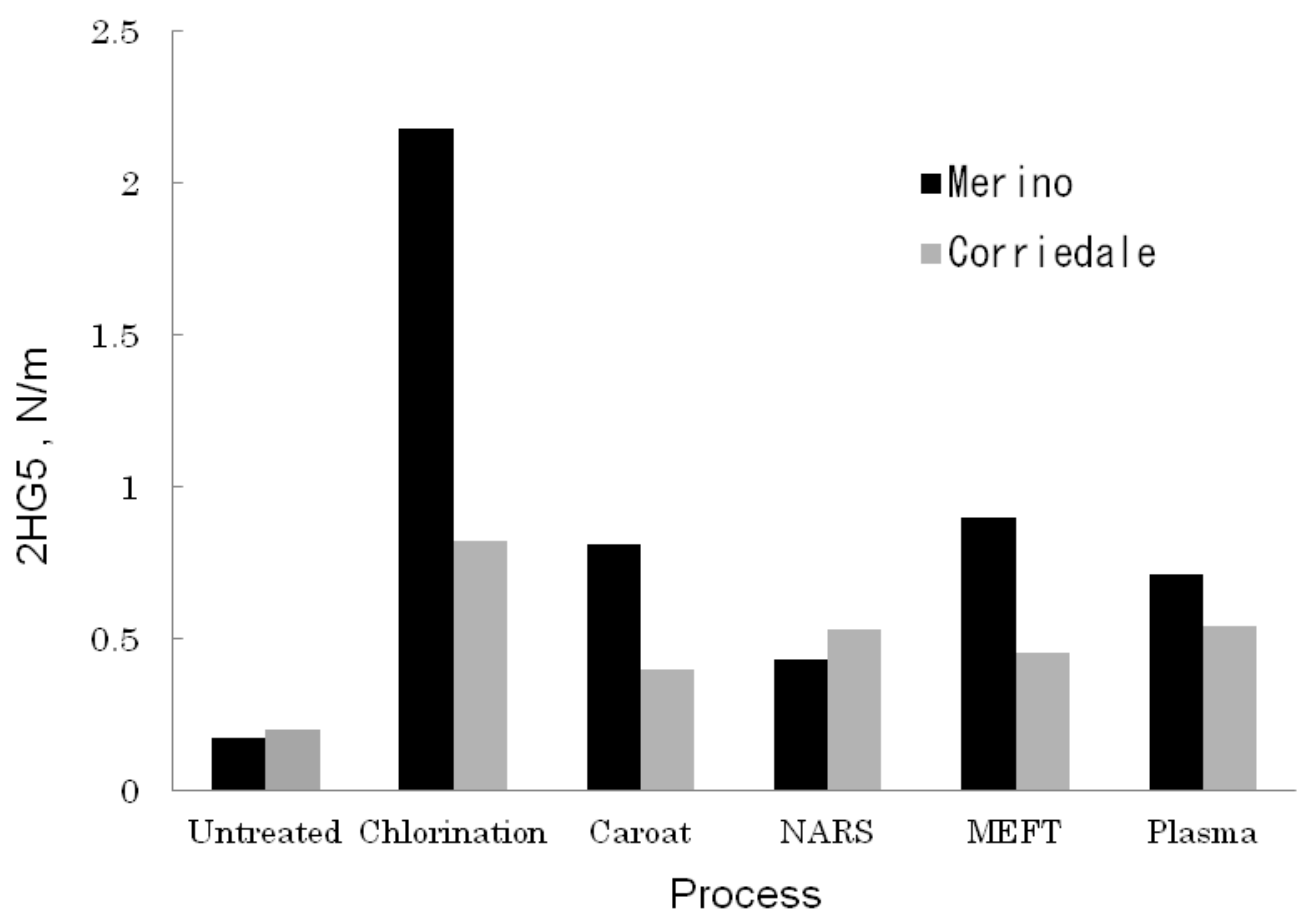

Fig.2 Comparison of shearing hysteresis, 2HG5 for untreated and treated fabrics. 

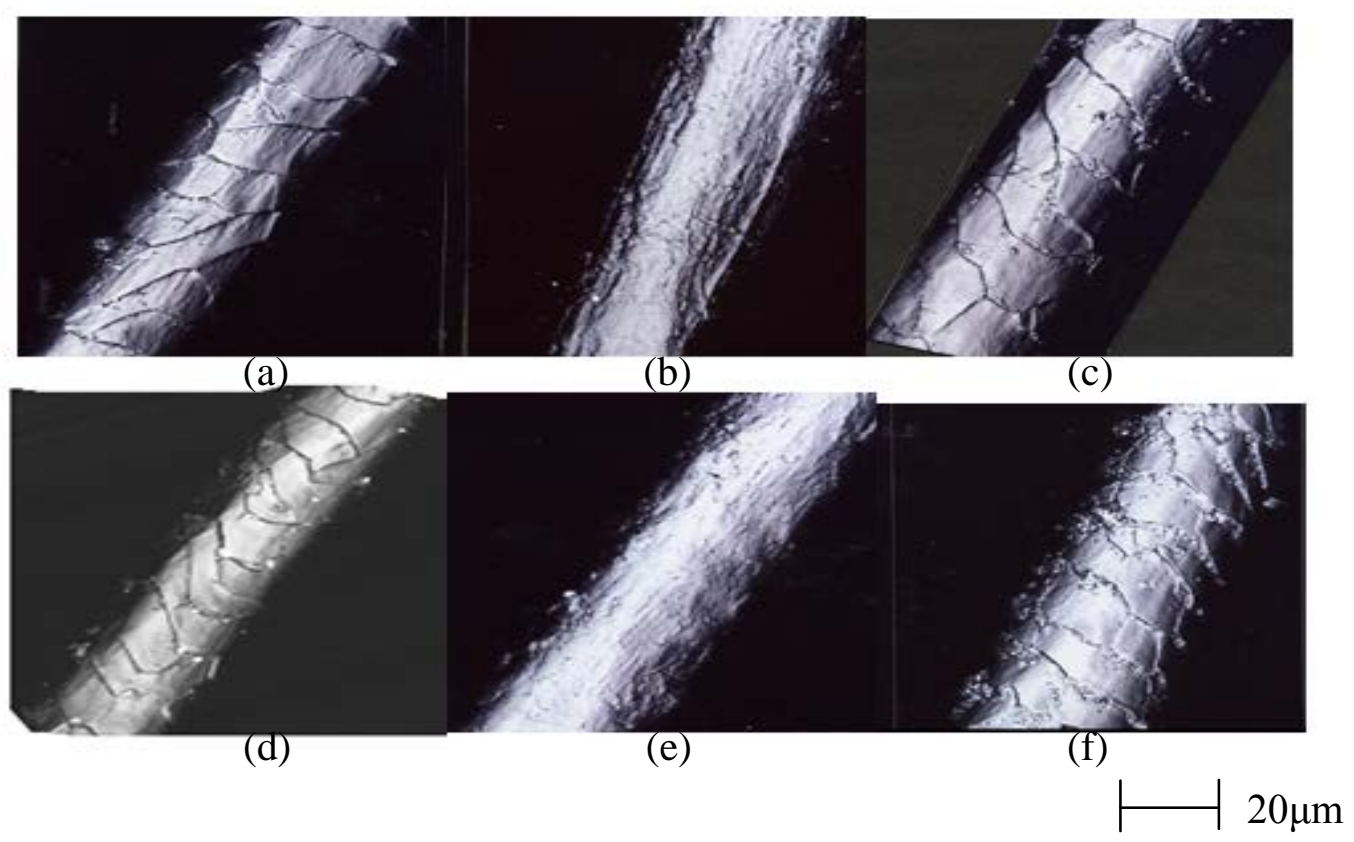

Fig. 3 Surface morphology of untreated and treated wool fibers: (a) Untreated, (b) Chlorination, (c) Caroat, (d) NARS, (e) MEFT, (f) Plasma.

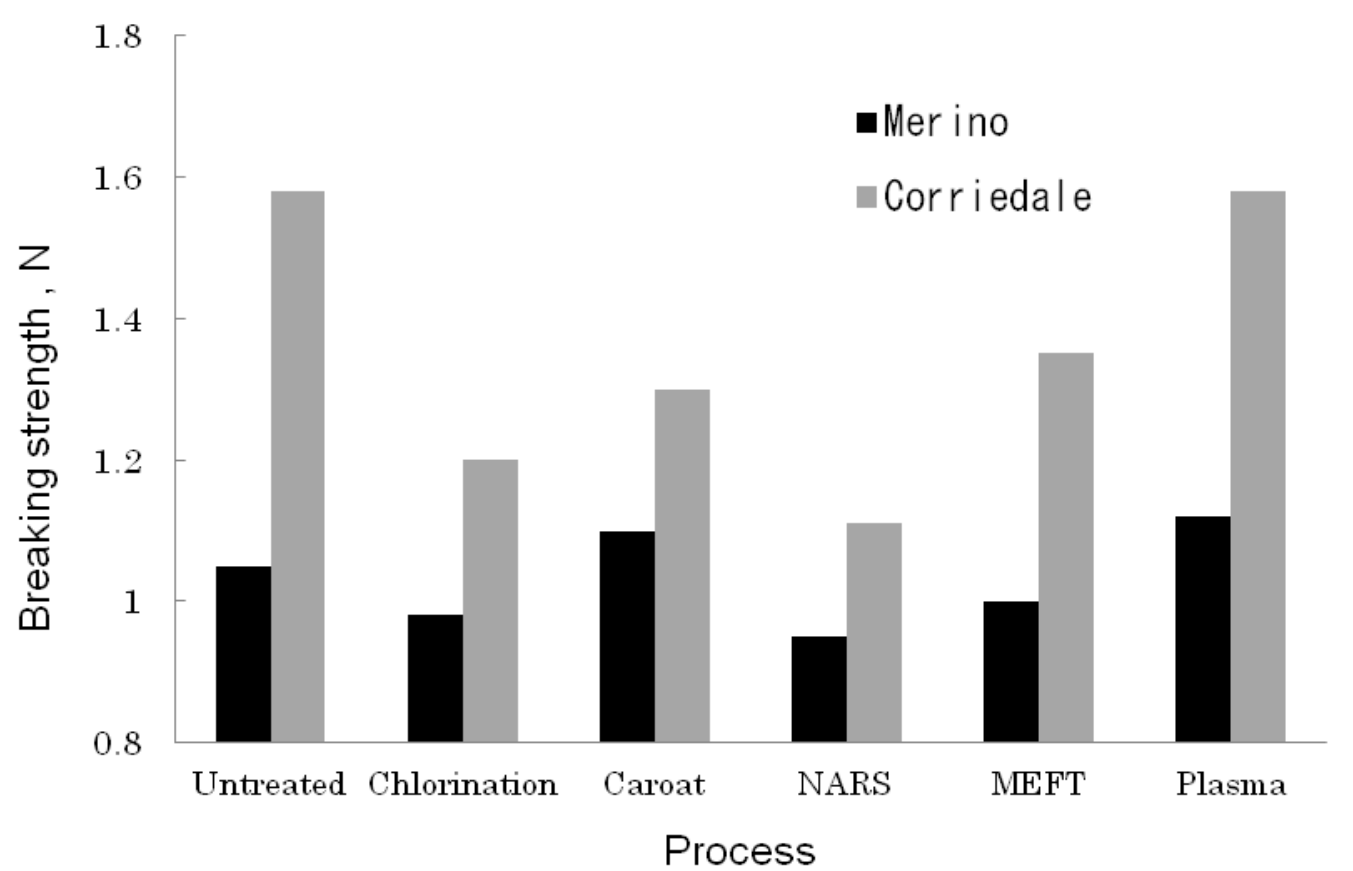

Fig. 4 Comparison of breaking strength for untreated and treated fabrics. 


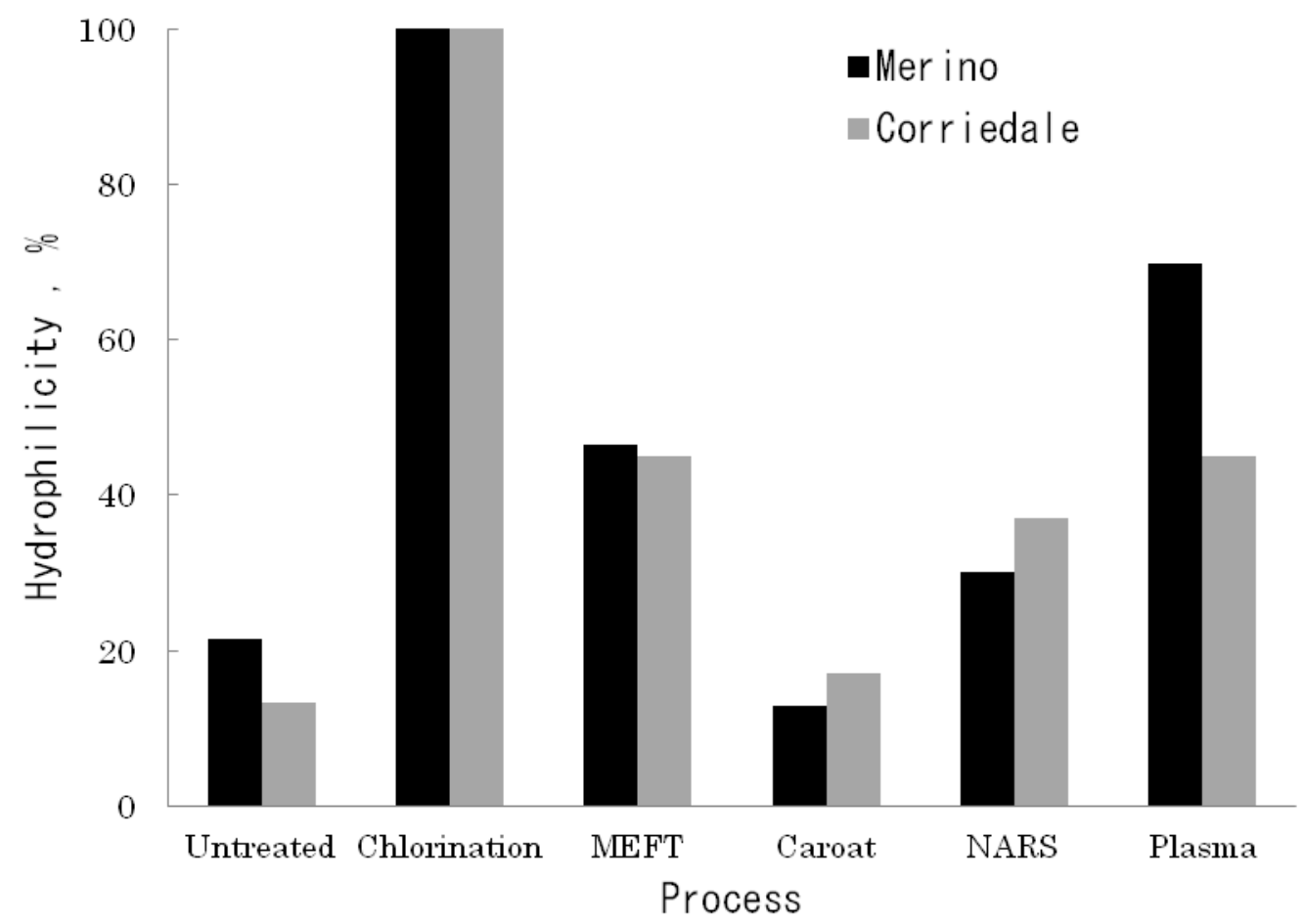

Fig.5 Comparison of hydrophilicity for untreated and treated fabrics.

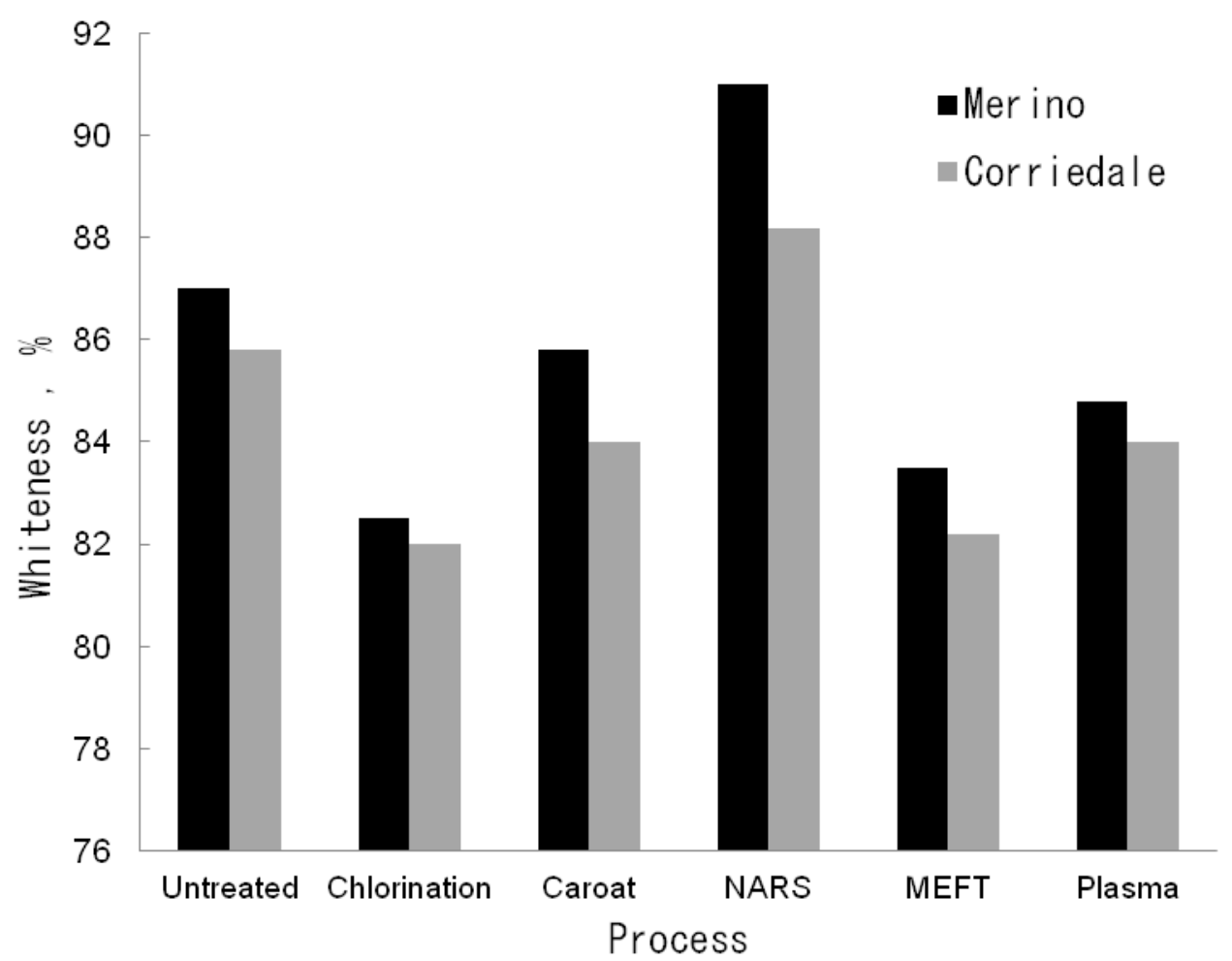

Fig.6 Comparison of Whiteness values for untreated and treated fabrics. 


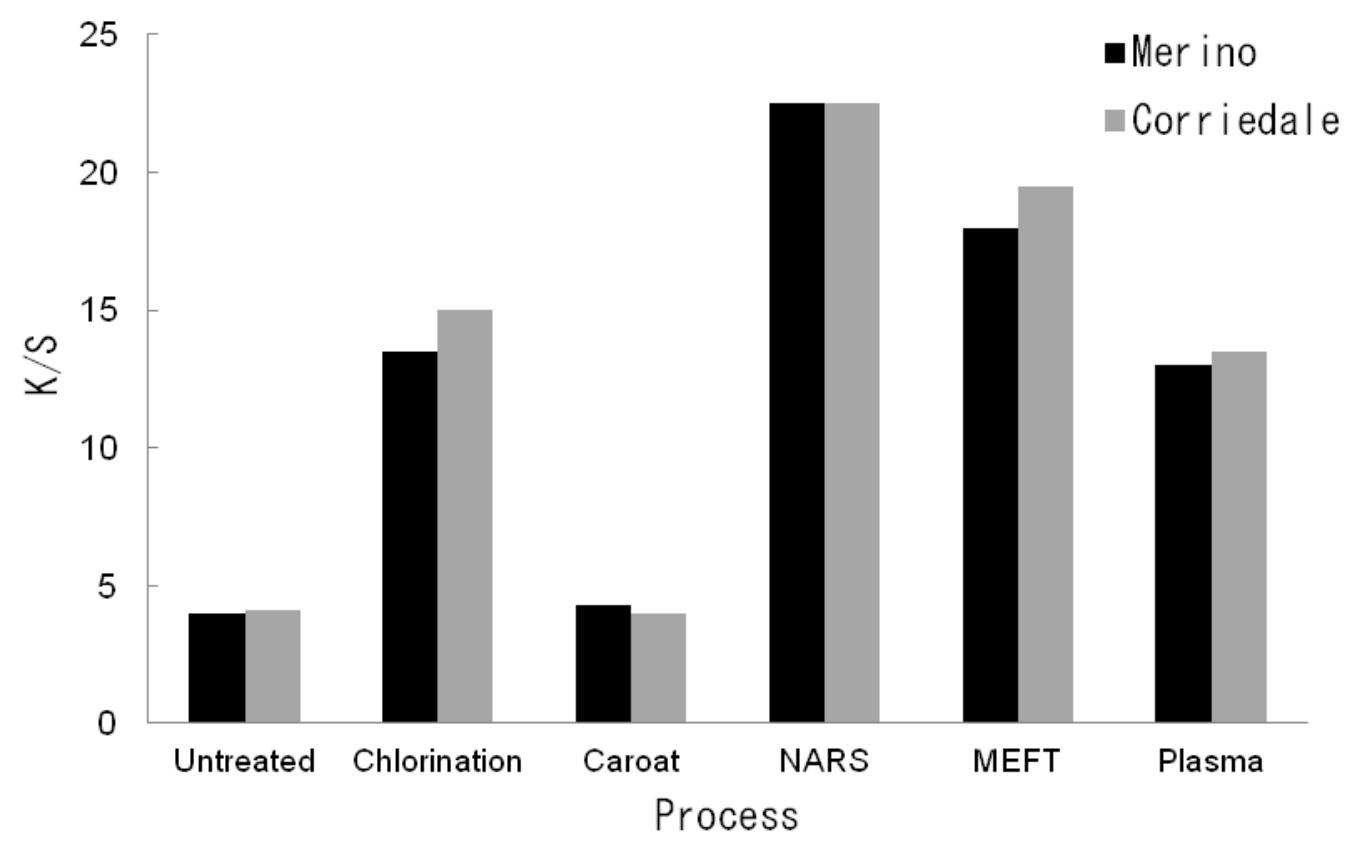

Fig.7 Comparison of K/S values for untreated and treated fabrics. 